\title{
Kajian Kebutuhan Elemen Desain Interior Toko Buku yang Diinginkan Masyarakat Urban sebagai Pendukung Eksistensi Toko Buku di Masa Depan. Studi Kasus pada Toko Buku di Surabaya.
}

\author{
Adi Wardoyo ${ }^{1}$, Frisda Azzarina ${ }^{2}$ \\ Dosen ${ }^{1}$, Mahasiswa ${ }^{2}$ Jurusan Desain Interior, Institut Teknologi Sepuluh Nopember, Surabaya, Indonesia \\ 1wardoyo.adi@gmail.com, ${ }^{2}$ fazzarina@yahoo.com
}

\begin{abstract}
ABSTRAK
Semakin berkembangnya toko buku online mengakibatkan masyarakat perkotaan lebih memilih untuk membeli jurnal online, e-book, atau majalah online daripada membeli buku di toko buku.Menurunnya minat masyarakat berkunjung ke toko buku memberi sebuah ide pada pebisnis untuk memperhatikan desain interiornya dan menambah fasilitas toko buku seperti ruang publik komersial lainnya seperti kafe dan sebagainya.

Tujuan penelitian ini untuk mengetahui kebutuhan fasilitas masyarakat urban yang dapat diaplikasikan untuk toko buku untuk mendukung eksistensi keberadaannya.Penelitian ini adalah penelitian diskriptif kuantitatif dengan pengambilan data melalui penyebaran kuisioner. Respondennya adalah masyarakat urban khususnya mahasiswa yang pernah mengunjungi toko buku.Berdasarkan penelitian ternyata kafe lebih diminati karena masyarakat urban lebih memilih berkunjung ke kafe dengan tujuan berdiskusi, meeting, atau mengerjakan tugas.
\end{abstract}

Kata kunci:Fasilitas, Desain interior, Toko buku,Urban

\section{ABSTRACT}

Because the impact of online bookshop, businessman prefer to buy online journals, e-books, or magazines online rather than buying books at the bookshop.Due to the declining interest of the community to visit the bookshop has given anidea to concern with the interior design and unify the bookshop with commercial public space such as café and so on.

The purpose of this study to describe the needs of urban communities facility that can be applied to support bookshop existence for future.This is descriptive quantitative research and collecting data via questionnaires. Respondents are urban communities, especially students who have visited the bookshop.Based on the research of cafes more desirable because urban people prefer a visit to the cafe with the purpose of discussing, meeting, or do the task.

Keywords:Facility, Interior Design,Bookshop,Urban

\section{PENDAHULUAN}

Toko buku yang menjadi obyek studi adalah sebuah toko buku yang menjual buku yang berhubungan dengan medis dan kesehatan yang terletak tidak jauh dari beberapa perguruan tinggi di daerah Surabaya timur. Letaknya yang dekat dengan beberapa perguruan tinggi sangat menguntungkan toko buku ini karena sangat dekat dengan kehidupan masyarakat urban, terutama di kalangan mahasiswa. Namun karena toko buku ini hanya menjual bukubuku yang berhubungan dengan medis sehingga pengunjung yang datang mayoritas hanya terbatas pada yang mencari buku medis saja. Untuk mempertahankan eksistensinya, Toko buku harus mem-perhatikan elemen interior pendukung dan menambah fasilitas lainnya agar menarik pengunjung lebih banyak lagi untuk datang. 
Penelitian ini bertujuan mengetahuifasilitas yang dibutuhkan masyarakat urban terhadap keberadaan toko bukusaat ini ditengah semakin berkembang dan diminatinya online shop. Hasil penelitian ini nantinya akan dikembangkan menjadi landasan desain yang dapat mendukung eksistensi keberadaan toko buku saat ini dan masa mendatang.

\section{METODOLOGI}

Penelitian ini adalah penelitian deskriptif kuantitatif dengan pengambilan data melalui penyebaran kuisioner. Respondennya adalah masyarakat urban khususnya mahasiswa yang pernah mengunjungi toko buku.

Sedangkan studi pustaka mengenai kafe dan perpustakaan diperoleh dari jurnal dan internet. Dari data yang diperoleh dapat menjadi landasan penciptaan suasana interior untuk mengembangkan potensi objek desain, sehingga bisa didapatkan desain interior yang sesuai dengan selera masyarakat urban khususnya mahasiswa yang merupakan target utama dari riset ini.

\section{HASIL DAN ANALISA}

Pada penelitian ini ingin diketahuisejauh mana desain interior toko buku membuat pengunjung yang merupakan masyarakat urban datang dan terkesan. Selain itu perlu diketahui aspek manakah dalam desain interior toko buku yang membuat masyarakat urban mengingat suatu tempat sehingga perlu dilakukan analisa tentang aktivitas dan kebiasaan masyarakat urban agartoko buku menarik untuk dikunjungi.

\section{A. Pandangan Masyarakat Urban terhadap Toko Buku.}

Tabel 1.Hal yang Menarik dalam Toko Buku.

\begin{tabular}{||c|l|c|c||}
\hline \hline No. & \multicolumn{1}{|c|}{ Pilihan } & Frekuensi (f) & Presentase (\%) \\
\hline 1 & Mengenai Produk & 2 & 5 \\
\hline 2 & Mengenai Nuansa Interior & 5 & 12,5 \\
\hline 3 & Mengenai Sirkulasi & 4 & 10 \\
\hline 4 & Mengenai Pencahayaan & 1 & 2,5 \\
\hline 5 & Tidak Terlalu Ingat & 1 & 2,5 \\
\hline 6 & $\begin{array}{l}\text { Tidak ada yang menarik, bahkan saya } \\
\text { lupa }\end{array}$ & 9 & 22,5 \\
\hline 7 & Tidak Menjawab & 5 & 12,5 \\
\hline 8 & Tidak pernah berkunjung & 13 & 32,5 \\
\hline & Jumlah & $\mathbf{4 0}$ & $\mathbf{1 0 0}$ \\
\hline \hline
\end{tabular}

Dari tabel 1 menunjukkan bahwa sekitar 22,5\% responden beranggapan toko buku tidak menarik sehingga tidak ada yang terkesan dari segi apapun dan sebanyak lima responden mengingat nuansa interior modern yang ditampilkan.

\section{B. Bentuk Ruangan Toko Buku.}

Tabel 2. Bentuk Ruang Toko Buku yang Terkesan Formal/Kaku

\begin{tabular}{||c|l|c|c||}
\hline \hline No. & \multicolumn{1}{|c||}{ Pilihan } & Frekuensi (f) & Presentase (\%) \\
\hline 1 & Sangat Setuju & 4 & 10 \\
\hline 2 & Setuju & 4 & 10 \\
\hline 3 & Cukup Setuju & 7 & 17,5 \\
\hline \hline
\end{tabular}




\begin{tabular}{||c|l|c|c||}
\hline \hline 4 & Tidak Setuju & 11 & 27,5 \\
\hline 5 & Sangat Tidak Setuju & 1 & 2,5 \\
\hline 6 & Tidak pernah berkunjung & 13 & 32,5 \\
\hline & Jumlah & $\mathbf{4 0}$ & $\mathbf{1 0 0}$ \\
\hline
\end{tabular}

Dari tabel 2 menunjukkan bahwa sekitar 27,5\% responden beranggapan toko buku tidak terlalu kaku, sehingga nuansa modern dalam toko buku adalah hal yang mereka anggap biasa. Sebanyak $17,5 \%$ responden cukup setuju apabila ruangan terkesan formal, dan masingmasing $10 \%$ beranggapan bahwa ruangan terlalu formal hanya untuk sebuah toko buku. Dengan ini diketahui bahwa masyarakat urban kurang menyukai hal-hal yang bersifat formal, akan lebih baik apabila bergaya modern dan tidak terlalu kaku.

Tabel 3. Bentuk Ruangan Toko Buku seperti Ruang Kesehatan/Klinik

\begin{tabular}{||c|l|c|c||}
\hline \hline No. & \multicolumn{1}{|c|}{ Pilihan } & Frekuensi (f) & Presentase (\%) \\
\hline 1 & Sangat Setuju, karena karakter & 6 & 15 \\
\hline 2 & Setuju, karena memang seharusnya & 8 & 20 \\
\hline 3 & Cukup Setuju & 3 & 7,5 \\
\hline 4 & $\begin{array}{l}\text { Tidak Setuju, karena lebih baik ada } \\
\text { sesuatu yang berbeda }\end{array}$ & 9 & 22,5 \\
\hline 5 & $\begin{array}{l}\text { Sangat Tidak Setuju, karena } \\
\text { membosankan }\end{array}$ & 1 & 2,5 \\
\hline 6 & Tidak pernah berkunjung & 13 & 32,5 \\
\hline \multicolumn{1}{|c|}{ Jumlah } & $\mathbf{4 0}$ & $\mathbf{1 0 0}$ \\
\hline
\end{tabular}

Dari tabel 3 menunjukkan bahwa sekitar 22,5\% responden beranggapan sebuah toko buku medis tidak harus bergaya seperti klinik atau rumah sakit, responden berharap sesuatu yang berbeda. Tetapi tidak jauh berbeda dari itu, sebanyak 20\% responden memang setuju apabila toko buku kesehatan memiliki gaya sebagaimana mestinya toko buku kesehatan sehingga dapat membedakan dengan toko buku lainnya. Dengan ini dibuatlah sebuah konsep dengan karakter klinik akan tetapi lebih trendi dengan penggunaan warna dan bentuk - bentuk yang unik.

\section{Pengembangan Fasilitas Toko Buku}

Tabel 4.Kesulitan Pengunjung dalam Mencari Buku Ketika Datang ke Toko Buku.

\begin{tabular}{||c|l|c|c||}
\hline \hline No. & \multicolumn{1}{|c|}{ Pilihan } & Frekuensi (f) & Presentase (\%) \\
\hline 1 & Sangat Setuju & 1 & 2,5 \\
\hline 2 & Setuju & 5 & 12,5 \\
\hline 3 & Cukup Setuju & 13 & 32,5 \\
\hline 4 & Tidak Setuju & 8 & 20 \\
\hline 5 & Sangat Tidak Setuju & 0 & 0 \\
\hline 6 & Tidak pernah berkunjung & 13 & 32,5 \\
\hline \multicolumn{2}{|r|}{ Jumlah } & $\mathbf{4 0}$ & $\mathbf{1 0 0}$ \\
\hline
\end{tabular}

Tabel 5.PerlunyaFasilitasKomputer untuk Membantu Penelusuran Buku.

\begin{tabular}{||c|l|c|c||}
\hline \hline No. & \multicolumn{1}{|c|}{ Pilihan } & Frekuensi (f) & Presentase (\%) \\
\hline 1 & Sangat Setuju & 10 & 25 \\
\hline 2 & Setuju & 15 & 37,5 \\
\hline 3 & Cukup Setuju & 2 & 5 \\
\hline 4 & Tidak Setuju & 0 & 0 \\
\hline 5 & Sangat Tidak Setuju & 0 & 0 \\
\hline 6 & Tidak pernah berkunjung & 13 & 32,5 \\
\hline \multicolumn{2}{|c|}{ Jumlah } & $\mathbf{4 0}$ & $\mathbf{1 0 0}$ \\
\hline \hline
\end{tabular}


Tabel 6. Perlunya Fasilitas Komputer untuk Mendownload E-book.

\begin{tabular}{||c|l|c|c||}
\hline \hline No. & \multicolumn{1}{|c||}{ Pilihan } & Frekuensi (f) & Presentase (\%) \\
\hline 1 & Sangat Setuju & 4 & 10 \\
\hline 2 & Setuju & 13 & 32,5 \\
\hline 3 & Cukup Setuju & 9 & 22,5 \\
\hline 4 & Tidak Setuju & 1 & 2,5 \\
\hline 5 & Sangat Tidak Setuju & 0 & 0 \\
\hline 6 & Tidak pernah berkunjung & 13 & 32,5 \\
\hline \multicolumn{2}{|r|}{ Jumlah } & $\mathbf{4 0}$ & $\mathbf{1 0 0}$ \\
\hline \hline
\end{tabular}

Dari tabel 4, ternyata sebanyak 32,5\% responden cukup kesulitan menemukan buku yang diinginkan. Diperkuat oleh hasil tabel 5 sebanyak 37,5\% responden sangat membutuhkan komputer penelusuran buku agar tidak bingung ketika mencari buku. Lalu dianalisa kembali dengan tabel 6, ternyata sebanyak 32,5\% juga membutuhkan komputer untuk informasi mengenai e-book. Dengan ini beberapa fasilitas dikembangkan untuk memudahkan pengunjung untuk mencari buku dan referensi lainnya.

\section{Kebiasaaan Masyarakat Urban}

Tabel 7.Tempat Berkumpul untuk Berdiskusi atau Belajar Selain di Rumah.

\begin{tabular}{||c|l|c|c||}
\hline \hline No. & \multicolumn{1}{|c||}{ Pilihan } & Frekuensi (f) & Presentase (\%) \\
\hline 1 & Perpustakaan & 15 & 37,5 \\
\hline 2 & Kafe & 20 & 50 \\
\hline 3 & Kampus & 1 & 2,5 \\
\hline 4 & Taman & 1 & 2,5 \\
\hline 5 & Kontrakan Temen & 3 & 7,5 \\
\hline \multicolumn{2}{|r|}{ Jumlah } & $\mathbf{4 0}$ \\
\hline
\end{tabular}

Dari 40 responden, pada tabel 7 menghasilkan data sebanyak 50\% masyarakat urban memilih kafe sebagai tempat pertemuan untuk melakukan diskusi, belajar, atau bekerja bersama rekan-rekan selain di rumah atau di kantor. Penulis ingin mengetahui penambahan fasilitas pada toko buku untuk menunjang minat masyarakat terhadap toko buku. Sehingga potensi toko buku dapat ditingkatkan dengan penambahan fasilitas seperti area baca dan kafe.

Tabel 8.Hal-hal yang Dilakukan di Tempat Nongkrong.

\begin{tabular}{||c|l|c|c||}
\hline \hline No. & \multicolumn{1}{|c|}{ Pilihan } & Frekuensi (f) & Presentase (\%) \\
\hline 1 & Begosip & 11 & 11 \\
\hline 2 & Mencari Suasana Menarik & 23 & 23 \\
\hline 3 & Mencari WIFI & 23 & 23 \\
\hline 4 & Membaca Buku & 21 & 22 \\
\hline 5 & Mengerjakan Tugas & 20 & 21 \\
\hline \multicolumn{2}{|c|}{ Jumlah } & $\mathbf{9 8}$ & $\mathbf{1 0 0}$ \\
\hline
\end{tabular}

Hal-hal yang dilakukan masyarakat urban apabila nongkrong di tempat favorit mereka sesuai dengan data tabel 8 adalah mencari suasana menarik, mencari wifi, membaca buku, dan mengerjakan tugas. Hasil jawaban diatas tidak begitu jauh. Dapat disimpulkan bahwa setiap masyarakat urban mengerjakan tugas atau membaca buku membutuhkan wifi, akan tetapi mereka sangat peka akan suasana yang mereka pilih. Sehingga suasana menjadi pilihan utama ketika memilih tempat nongkrong. Dari data tersebut penulis ingin membuat suatu toko buku yang dapat mencakup aktivitas tersebut. Penulis merasa toko buku adalah tempat yang sangat tepat sehingga nilai fungsi toko buku semakin meningkat. 


\section{E. Preference of Urban Communities}

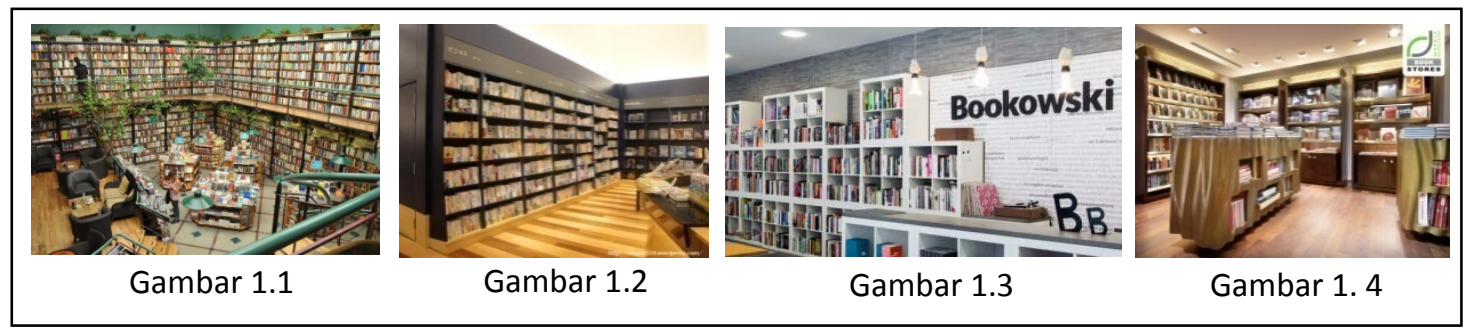

Gambar 1. Gambar Pilihan Pertanyaan untuk Tabel 9. Sumber :www.pinterest.com

Tabel 9.Suasana Toko Buku yang di Sukai

\begin{tabular}{||c|c|c|c||}
\hline \hline No. & \multicolumn{1}{|c|}{ Pilihan } & Frekuensi (f) & Presentase (\%) \\
\hline 1 & Gambar 1.1 & 16 & 40 \\
\hline 2 & Gambar 1.2 & 9 & 22,5 \\
\hline 3 & Gambar 1.3 & 11 & 27,5 \\
\hline 4 & Gambar 1.4 $\quad$ Jumlah & 4 & 10 \\
\hline & \multicolumn{2}{|c|}{$\mathbf{4 0}$} & $\mathbf{1 0 0}$ \\
\hline
\end{tabular}

Dari tabel 9, ternyata sebanyak 40,5\% responden lebih menyukai gambar 1.1 yaitu desain interior yang menghadirkan suasana alam hijau dalam ruangan daripada konsep modern. Akan tetapi tidak beda jauh dengan itu, sebanyak 27,5\% responden masih menyukasi suasana modern yang trendy masa kini dengan tipografi dan bentuk dengan garis-garis halus yang simpel. Penulis ingin mengetahui selera desain dari masyarakat urban saat ini. Ada kemungkinan apabila suasana penghijauan digabungkan dengan suasana trendy dengan penerapan gambar-gambar dan tipografi.

Tabel 10.Posisi Favorit anda Ketika Membaca

\begin{tabular}{||c|c|c|c||}
\hline \hline No. & Pilihan & Frekuensi (f) & Presentase (\%) \\
\hline 1 & Fleksibel & 25 & 62,5 \\
\hline 2 & Sudut Ruangan & 10 & 25 \\
\hline 3 & Dekat Spot Menarik & 5 & 12,5 \\
\hline & Jumlah & $\mathbf{4 0}$ & $\mathbf{1 0 0}$ \\
\hline \hline
\end{tabular}

Dari tabel 10, sebanyak 62,5\% responden adalah seorang yang fleksibel. Bahkan angka ini sangat menonjol dibanding pilihan lainnya. Hal ini membuktikan bahwa masyarakat urban saat ini adalah orang yang mudah bergaul dan supel. Dengan ini penulis dapat membuat beberapa elemen-elemen desain yang dapat berpindah pindah.

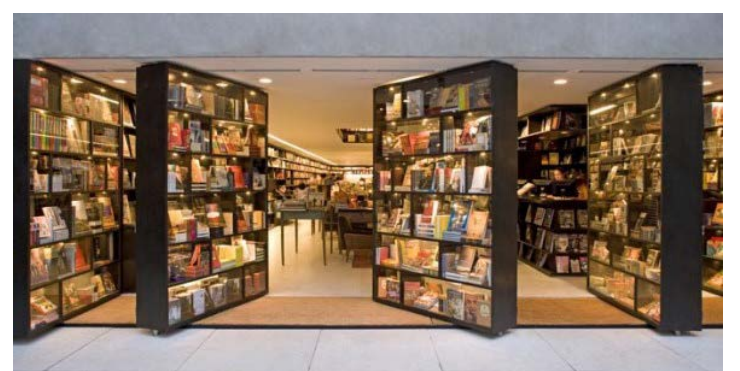

Gambar 2.Contoh Aplikasi Rak Toko Buku yang bisa Berpindah-pindah. Sumber :www.pinterest.com 
Tabel 11. Pada Saat Membaca Atau Mengerjakan Tugas Lebih Menyukai Tempat yang Tidak Berisik.

\begin{tabular}{||c|c|c|c||}
\hline \hline No. & Pilihan & Frekuensi (f) & Presentase (\%) \\
\hline 1 & Sangat Setuju & 10 & 25 \\
\hline 2 & Setuju & 18 & 45 \\
\hline 3 & Cukup Setuju & 10 & 25 \\
\hline 4 & Tidak Setuju & 1 & 2,5 \\
\hline 5 & Sangat Tidak Setuju & 1 & 2,5 \\
\hline \multicolumn{2}{|l}{} \\
\hline
\end{tabular}

Dari tabel 11, sebanyak 45\% responden cukup peduli akan ketenangan saat belajar. Penulis menjadi tahu bagaimana membuat publik area tenang walaupun dalam keadaan ramai,misalnya dengan pemberian sekat disetiap meja diskusi.

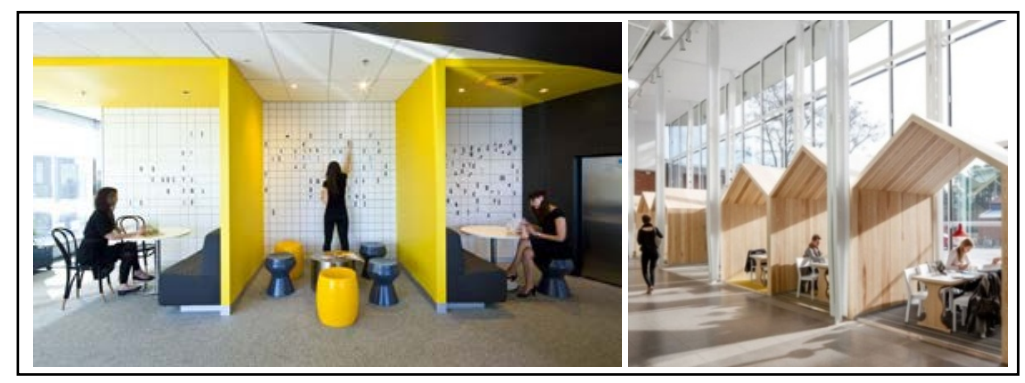

Gambar 3. Contoh Ruang Membaca yang Diberi Sekat-Sekat. Sumber :www.pinterest.com

Tabel 12.Suasana Coffee Shopyang Disukai dari Gambar 4.

\begin{tabular}{||c|c|c|c||}
\hline \hline No. & \multicolumn{1}{|c|}{ Pilihan } & Frekuensi (f) & Presentase (\%) \\
\hline 1 & Gambar 4.1 & 10 & 25 \\
\hline 2 & Gambar 4.2 & 3 & 7,5 \\
\hline 3 & Gambar 4.3 & 23 & 32,5 \\
\hline 4 & Gambar 4.4 & 3 & 7,5 \\
\hline 5 & Gambar 4.5 & 15 & 37,5 \\
\hline & \multicolumn{1}{|c|}{ Jumlah } & $\mathbf{4 0}$ & $\mathbf{1 0 0}$ \\
\hline \hline
\end{tabular}

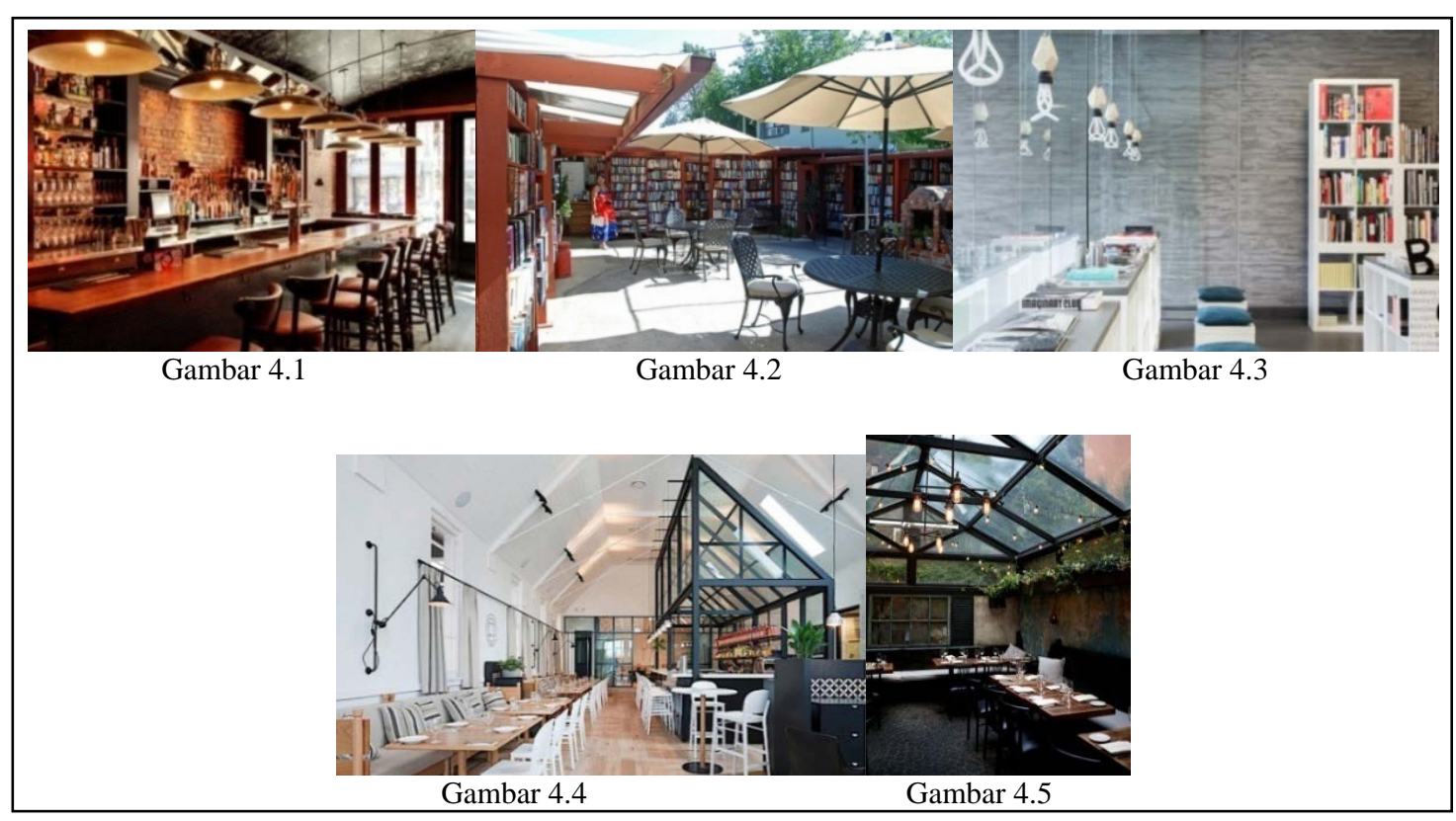

Gambar 4. Pilihan Gambar Tabel 4.4

Sumber :www.pinterest.com 
Dari tabel 12 ternyata sebanyak 37,5\% responden lebih menyukai suasana alam hijau dalam ruangan dengan bentuk furnitur sedikit elegan. Akan tetapi tidak jauh beda dengan itu sebanyak 32,5\% responden menyukai material-material kayu natural pada interior. Untuk itu diciptakan suatu suasana interior yang simple dengan material-material natural yang dikombinasikan dengan tanaman hijau. Berikut ini adalah keterangan gambar yang dipilih oleh responden.

Berdasarkan pengembangan data-data diatas diketahui bahwa masyarakat urban khususnya mahasiswa memiliki karakter modern, bebas, dan baru. Desain interior toko buku dapat dikembangkan dengan bentuk-bentuk elemen desain dengan konsep natural yang melambangkan kebebasan ditengah padatnya aktivitas masyarakat urban. Konsep natural desain interior dengan pengaplikasian material alam diimbangi dengan beton ekspos yang mewakili bentuk modern. Untuk mendukung kesan modernditerapkan konsep bentuk-bentuk elemen desain yang sederhana dengan garis-garis halus sertapemakaian dominan warna putih untuk menekankan karakteristik toko buku medis yang menggambarkan karakter masyarakat urban yang modern dan simple. Agar desain interior toko buku berkesan dan menarik perhatian masyarakat urban untuk berkunjung di tengah kesibukan aktifitasnya maka diperlukan bentukan yang nyentrik. Selain itu penambahan fasilitas seperti area diskusi dan kafe untuk memfasilitasi pengunjung dalam mencari suasana yang baru juga diterapkan sebagai potensi toko buku yang berada di pusat kota khususnya daerah perkuliahan mahasiswa. buku.

Berikut ini adalah sketsa gambar yang merupakan gagasan ide untuk desain interior toko

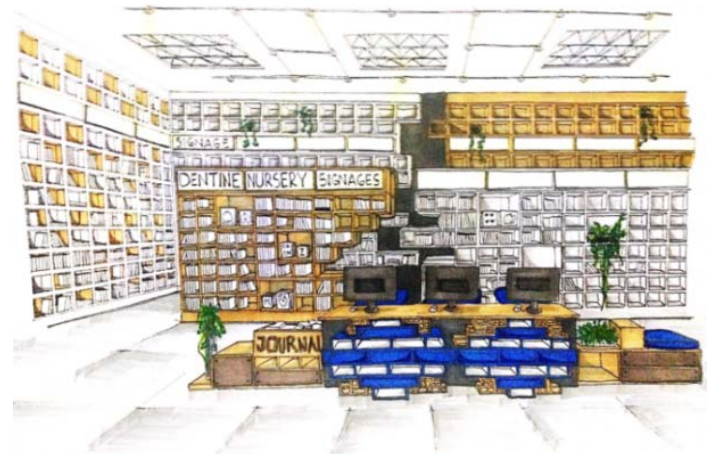

Gambar 5. Sketsa Gagasan I

Sumber : Dokumentasi Penulis (2015)

Pada gambar 5 adalah sketsa yang menjelaskan suasana utama toko buku, dengan konsep yang sudah dijelaskan sebelumnya.

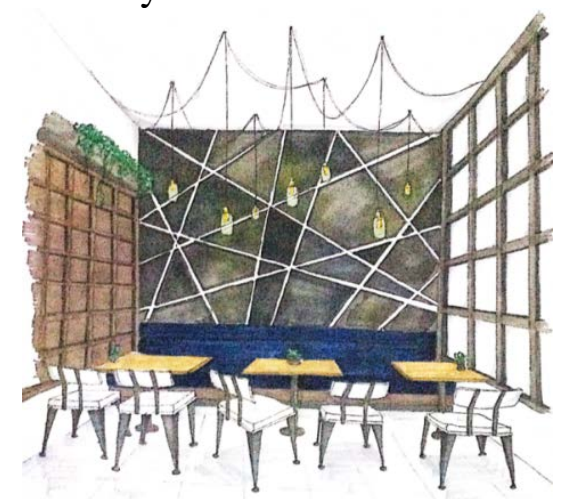

Gambar 6. Sketsa Gagasan II

Sumber : Dokumentasi Penulis (2015) 
Pada gambar 6 adalah sketsa yang menjelaskan penambahan fasilitas dengan penggunaan pencahayaan alami dan material-material natural sesuai dengan selera masyarakat urban yang menginginkan kebebasan. Elemen desain lain juga menggunakan bentuk yang unik dengan warna-warna corporate image toko buku yaitu biru dan putih.

\section{KESIMPULAN}

Toko buku medis yang berlokasi di Surabaya timuradalah merupakan toko buku yang berada di pusat kota yang sangat dekat dengan aktivitas masyarakat urban khususnya mahasiswa sehingga memiliki potensi untuk penambahan fasilitas seperti area pertemuan, kafe, area baca, diskusi dan jualbeli buku elektronik. Konsep desain toko buku ini disesuaikan dengan karakter segmentasi pembelinya yang mayoritas adalah mahasiswa perkotaan sehingga mudah dikenali. Akan tetapi diharuskan dibuat berbeda agar tidak monoton sebagai suatu bentuk gaya sebuah klinik. Untuk itu dipilih warna-warna putih pada bentukan elemen desain sebagai point of view sebuah toko buku medis.

Mayarakat urban khususnya mahasiswa memiliki karakter yang menginginkan kebaruan, untuk itu konsep desain interior toko buku yang disarankan adalah gaya urban yang memiliki karakteristik modern dan unik dengan warna-warna sederhana. Dominasi finishing yang digunakan adalah mengkilap (glossy)sesuai dengan karakteristik sifat baru dari masyarakat perkotaan. Karakter masyarakat urban yang menginginkan suasana 'kebebasan'diantara banyaknya peraturan menjadikan konsep yang dipilih adalah konsep natural alam yang dikombinasikan dengan material beton yang kuat sebagai simbol ketegasan peraturan. Penggunaan material-material alam dan tumbuhan hijau akan memberikan kesegaran di tengah hiruk pikuk perkotaan.

\section{PUSTAKA}

[1] Arikunto, Suharsimi. 2006. Metodelogi penelitian. Yogyakarta: Bina Aksara.

[2] Januardani, Adinda. Jurnal Tingkat Sarjana bidang Senirupa dan Desain. FSRD ITB.Bandung

[3] Sugiyono. 2003. Metode Penelitian Bisnis. Bandung. Pusat Bahasa Depdiknas

[4] Wardhana, Mahendra. NSLAnalysisMethodDevelopmentinEnvironmentFacilityto AchievePublicConvenienceandHumanCirculation Security. ITS Research 2014;Unpublished. ITS. Indonesia.

[5] URL : www.pinterest.com

[6] URL : www.dazeen.com 